\title{
Off-Line and User-Oriented Approach for Supplier Selection in Dynamic Environment: A Case Study in the Healthcare Services
}

\author{
Shalom Moalem ${ }^{1}$, Avi Herbon ${ }^{1,2}$, Haim Shnaiderman ${ }^{1}$, Joseph Templeman ${ }^{3}$ \\ ${ }^{1}$ Department of Management, Bar-Ilan University, Ramat-Gan, Israel; ${ }^{2}$ Department of Management and Industrial Engineering, Ariel \\ University Center of Samaria, Ariel, Israel; ${ }^{3}$ Joseph Templeman, The College of Business Administration, Rishon LiTzion, Israel. \\ Email: Email: avher@bezeqint.net
}

Received August 19 ${ }^{\text {th }}, 2010$; revised October $4^{\text {th }}, 2010$; accepted November $10^{\text {th }}, 2010$.

\begin{abstract}
Evaluating and selecting supplies are critical activities in the process of purchasing and supplying materials. Many manufacturing and service organizations operate in a constantly changing business environment and occasionally have to reconsider their steps in terms of supplier selection. This paper offers a methodology that takes into account the impact of a dynamic business environment on the supplier selection process. This methodology represents an applicable tool supported by decision for the planned selection of a single supplier that changes with time out of a supplier group over a finite planning horizon. The suggested methodology has been tested in a large Israeli organization-Clalit Health Services, which comprises large-scale logistical entity working with hundreds of suppliers on an ongoing basis. Our analysis of application results shows that the suggested strategy of switching suppliers over a predefined planning horizon according to the business environment forecast is over $10 \%$ more efficient compared to a strategy that does not change the leading supplier throughout the planning horizon. This average improvement is translated into expected efficiency gains on most operative dimensions which represent selection parameters, such as cost per unit, supply lead-time, reputation and more. Nevertheless, some of their value is lost due to some dimensions.
\end{abstract}

Keywords: Supplier Selection, Dynamic Environment, Case Study, Healthcare Services

\section{Introduction}

\subsection{Supplier Selection}

Manufacturing and service organizations contract with external suppliers for the products or services which they market. These may be raw material, finished products or service suppliers. Selecting the right supplier is a complex decision made by companies and organizations, with potentially significant impact on the organization's ongoing performance. Many studies [1,2] have indicated that finding the right suppliers is essential for business organizations and crucial to their success. It affects critical areas along the organization's supply chain, such as production, transportation, inventory, and quality. By selecting the right suppliers, the organization can gain in efficiency and enhance supply chain cost-effectiveness. On the other hand, failing to select the right suppliers could compromise the organization in economic/financial terms or in terms of service quality and reputation. A key tool in supplier selection is supplier ranking, which is a central aspect of the quality management field, and is attracting growing attention nowadays [3].

One of the key characteristics of the business environment in which most organizations currently operate is its dynamics. These dynamics are a significant and decisive aspect of business environmental uncertainty $[4,5]$. Environmental dynamics are governed by several factors, including consumer behavior, and predictable or unpredictable events in the local or global business environment. Today's customers are typically more sensitive to quality, more exposed to competition and hence more demanding in terms of requiring higher quality standards and better value for money. The intense competition enables them to demand quicker and more customized response, which directly impacts the dynamics of the business environment. Another important factor is the rapid advances in information technology which allow for cost reduction, shorter supply times, informational reliability and accelerated manufacturing and procurement processes, along with more streamlined integration of opera- 
A Case Study in the Healthcare Services

tional processes with marketing and customer service approaches.

Financial parameters also affect the dynamics of the business environments. For example, in a dynamic business environment manufacturing or service organizations contract with suppliers from many different countries, contracts affected by exchange rate fluctuations. Another important financial factor is changes in interest rates, which may affect inventory maintenance costs. These changes often affect supplier selection considerations, since the cost of products or services provided by the supplier is related to the interest rate.

\subsection{Review of Supplier Selection Methods}

The supplier selection technique literature is extensive, including numerous studies beginning in the 1960's [6] for a comprehensive review of early works. These techniques include using satisfaction level categories to rank suppliers, relying mainly on the experience and skills of the procurement manager charged with selecting a supplier [7]. Other techniques discussed in the literature are elimination [8], which specifies minimal standard scores for each supplier selection criterion, as well as various models of linear combinations of criteria weights used to evaluate suppliers [9-11]. Common selection criteria are price, quality and due-dates. The criteria specified by Dickson [11] remain relevant to this day, although their relative importance has changed. Another technique relies on converting selection criteria to cost units based on a pricing of various activities, to produce a single, total cost [12]. Finally, the AHP (analytic hierarchy process) technique enables decision makers to use comparative quality assessments instead of qualitative indicators based on precise weight calculations [13].

The literature also offers many mathematical programming models, including linear programming [14], MIP (mixed integer programming) [15], non-linear programming [16], MOP (multi-objective programming) [17], and AHP models [18].

Probabilistic and statistical models are also common. Soukup [19] suggests a supplier selection methodology requiring the decision maker to estimate the probability of obtaining future supplier performance evaluation given certain scenarios. Liao and Rittscher [20] suggest a genetic model designed to enhance supplier flexibility in the supplier selection process given normally distributed random demand and capacity constraints with the acceptable assumption that such enhancement would contribute to greater flexibility throughout the supply chain. In a case study of replacing the bus fleet of a large organization, Keles and Hartman [21] used an MIP model and sensitivity analysis to obtain an optimal solution for dynamic business environment changes. The objective of this study was to determine optimal long-term timetables for replacing the old bus fleet, with several manufacturers submitting proposals.

To conclude, note that as already mentioned the literature lacks direct reference to the dynamic nature of the business environment as a key characteristic informing the supplier selection process.

\subsection{The Need for a New Supplier Selection Me- thodology: The Clalit Case}

Supplier selection is directly affected by factors related to the suppliers and to the nature of supply. According to our approach, supplier selection should also be affected by multiple exogenous factors such as demand and supply, which characterize a dynamic business environment. Dynamic change in parameter values characterizing the business environment represents a change in environmental conditions which could make decision makers consider replacing the present supplier or selecting further suppliers. For example, a supplier deemed irrelevant in the past could become relevant due to the falling exchange rate of a certain currency and the resulting reduced procurement cost. Despite the critical importance of the supplier selection process, however, there are still many organizations which do not conduct structured supplier selection processes. Many organizations rely exclusively on economic parameters when selecting their suppliers.

The bulk of studies on supplier selection do not enable corporate decision makers to practically deal with changes resulting from the dynamic nature of the business environment, changes that often require rapid response. At the same time, many organizations in Israel and abroad operate under conditions of a constantly changing business environment which requires them to reconsider their decisions at a much higher rate than in the past.

The present study presents a supplier selection methodology applied in retrospect to data provided by a large Israeli HMO-Clalit Health Services (CHS). This organization comprises Supply and Procurement Administrations which are among the largest in the Israeli economy, serving some $60 \%$ of the Israeli population. As these work with hundreds of suppliers on an ongoing basis, making an efficient supplier selection process is highly important to them. In view of the common approaches to this problem which lacked sufficient reference to environmental dynamics, however, CHS has clung to lessthan-optimal suppliers without any practical option of replacing them, or with the ability to replace them only by incurring a high financial penalty.

The CHS supply and Procurement Administrations 
purchase medicines and medical hardware and distributes them to customers. The Supply Administration works with some 350 suppliers, with about 2,000 supply points, and with more than 5 million units of 5,000 items provided annually, for a total value of around 3.1 billion NIS ( $\$ 840 \mathrm{~m}$ in current values).

The specific product selected for applying the suggested methodology is latex gloves. Latex is a milky fluid derived from the rubber tree and processed to its finished form. This product is in high demand among CHS customers. Its price is affected by environmental factors such as sharp raw material cost fluctuations, and struggles over controlling the processing industry. Any shortage of latex glove supply could mean immediate suspendsion of all medical activities in operating rooms and laboratories. At the same time, unexpected environmental changes could significantly affect CHS's positioning vis-à-vis latex suppliers. For example, due to environmental changes-mainly reduced raw material supply - during 2004-2007, raw material costs have skyrocketed, and due to CHS's long-term contractual commitment to the supplier of this market-dependent item, it had to pay premium prices. This meant that further business relations with that supplier were no longer worthwhile, and that a new supplier needed to be found, which could better meet the environmental changes. However, lack of preparation to the predictable rise in the item's price made it difficult for CHS to immediately replace the supplier, leading to high expenses and a lower service level. We suggest that such environmental dynamics should be factored into the organization's decision making already at the supplier selection stage.

\subsection{Study Framework}

The present study discusses a representative supplier selection case as a model for large organizations contracting with a wide variety of suppliers and operating in a dynamic business environment. Our objective is to apply a methodology for selecting a single supplier at any point in time over a given planning horizon under dynamic environmental conditions, while enhancing management indicators commonly used in supplier selection. As presented below, supplier selection is the responsibility of a single decision maker or a single representative of a team of decision makers in a manufacturing or service organization interested in selecting a proposal by a single supplier among a large number of concurrent proposals, $i=1,2, \cdots, S$. The selection process will be based on several evaluation criteria, used by the decision maker to subjectively evaluate each proposal. The dynamic business environment is represented by several quantitative (environmental) parameters, $j=1,2, \cdots E$, whose value could change with time.

Part 2 describes CHS and its present supplier selection procedure. Part 3 details the methodology for constructing dynamic weights as a key element in the supplier selection process. In Part 4 we present the results of our case study application. Finally, our findings are discussed in Part 5.

\section{Supplier Selection at Clalit Health Services}

\subsection{Background}

Clalit Health Services (CHS) is the largest HMO in Israel, providing medical services to over 3.7 million customers through more than 1,200 clinics, 14 hospitals, some 400 pharmacies, and hundreds of institutes and labs. Its professional staff includes thousands of physicians, nurses, pharmacists, and paramedics.

The present study focuses on CHS's Supply and Procurement Administrations. The Supply Administration is a key element in the organization's logistical function, as it is in charge of inventory management and supplying medical institutes. The Procurement Administration's main responsibilities include initiating and managing procurement contracts, constructing infrastructures and developing management and control systems based on market surveys, selecting potential sources and suppliers, creating competition and taking advantage of inherent economies of size. The fundamental concept of CHS's procurement processes is to secure a high-quality accurate procurement channel at minimal cost and maximal flexibility. The Procurement Administration follows several guidelines, including compliance with medicine prescription authorization requirements, meeting the requirements of professional committees, meeting standard safety requirements, reliability and first-rate financial terms. Once potential sources and suppliers are identified, the administration is required to specify the contractual relationship with them. The tender technique is applied based on CHS's obligatory tender procedure, according to which a dedicated tender committee evaluates the various suppliers in a tender procedure for procuring the hardware in question. Committee members include a comptroller representative, a member of the public, a buyer, a financial executive, an economist and the head of the relevant department.

The specific product referred to in this case study is latex gloves (see Figure 1). Latex is a milky fluid derived from certain plants and processed using various methods to its finished form. The most important latex ingredient is produced from the Hevea brasiliensis tree, also called "gum tree" (see Figure 2). Many products 
A Case Study in the Healthcare Services

used in medicine and science, as well as every- day life, are made of or contain latex. Apart from gloves, they include ventilation masks, operating room equip- ment, dental medicine equipment, balloons, toys, balls and condoms.

Latex gloves are in high demand among CHS customers. Their price is influenced by environmental factors such as raw material cost fluctuations and struggles for control of the processing industry. Glove shortage could mean suspension of operating room and laboratory activities. In 2002, a supply contract was signed with one of this product's suppliers based on contemporary demand and consumption forecasts. The contract period was five years, without an option for reevaluation based, among other things, on changes in the business environment.

The following years saw regulatory changes in the producing countries, such that some of them banned all latex exports to the west. These environmental changes meant lower raw material supply and made continuous production of latex gloves more difficult, leading to skyrocketing costs. The international market price of $100 \mathrm{~g}$ of latex was $\$ 0.91$ in early 2004 , rising to $\$ 1.4$ in early 2007. Following these changes, the glove supplier decided to raise the unit price during the contract period, without any negotiation with CHS representatives, taking advantage of the rigid contract.

It was such extreme environmental fluctuations, particularly those which lead to the unilateral steps taken by the supplier of this product, which motivated our choice of latex gloves to demonstrate the application of our proposed methodology. When examining the decision making process leading to this supplier's selection in late

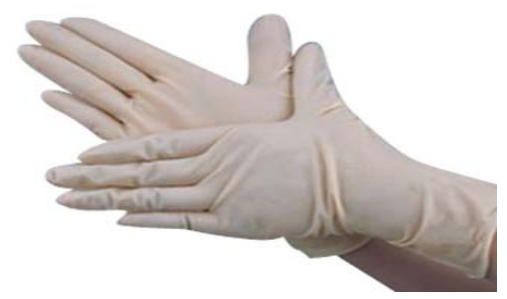

Figure 1. Latex gloves.

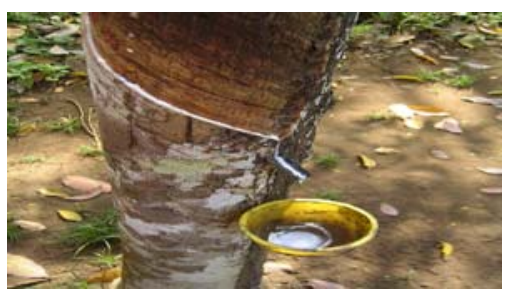

Figure 2. Latex raw material.
2002, we will also look into the option of changing suppliers in the future based on forecasts of predictable environmental changes.

\subsection{Supplier Proposals}

In 2002, the CHS Procurement Administration began a process of selecting latex glove suppliers. The product is particularly in demand in the medical community, with monthly consumption of some $1 \mathrm{~m}$ units. An RFP was sent to four suppliers $(S=4)$, designated hereafter as $S 1$, $S 2, S 3$ and $S 4$. The price offers were requested per a 100 glove unit. The suppliers were also requested to meet various selection parameters according to CHS requirements, based on Procurement Administration policy. These commonly used criteria included cost, quality, supply rate and flexibility [22]. In turn, the suppliers' proposals were translated to selection parameter values.

Appendix 1 presents these selection parameters and their values, based on the suppliers' proposals. The Reputation parameter refers to historical supplier performance data. In the absence of such data, the supplier in question will be evaluated without any consideration of this parameter. The Credit Rating parameter refers to the supplier's economic strength and financial stability, and is measured using a 1-5 Likert scale based on financial data required of the supplier. Geographic Location refers to the distance, in kilometers, between the suppliers' and the customers' warehouses. Finally, the Payment Deadline refers to the latest date following the end of a current work month in which the supplier demands a financial return for the supplies delivered during that month.

After specifying the customer's requirements, the suppliers' proposals were translated into measurable data by composing a supply criteria list, $k^{1}=1,2, \cdots Q_{1}, q_{k^{1}}^{1}$ (Set 1 ), in which each criterion is made up of several relevant parameter indicators, $p_{k^{1}, n^{1}}^{1}, n^{1}=1,2 \cdots P_{k^{1}}^{1}$. The supplier criteria list was specified in a similar way $q_{k^{2}}^{2}, \quad k^{2}=1,2, \cdots Q_{2}$ and designated Set 2, with each criterion made up of relevant parameters, $p_{k^{2}, n^{2}}^{2}$, $n^{2}=1,2 \cdots P_{k^{2}}^{2}$. S2 proposed a discount (for the whole amount), based on the number of units purchased in each order, as illustrated in Table $\mathbf{1}$ below.

Table 1. S2 Unit cost based on order size.

\begin{tabular}{cc}
\hline Order Size & Cost per $\mathbf{1 0 0}$ Units (NIS) \\
\hline $3,000,000-100,000$ & 18 \\
$9,000,000-3,000,001$ & 15 \\
$15,000,000-9,000,001$ & 12 \\
\hline
\end{tabular}




\subsection{Supplier Proposals}

After receiving the supplier proposals and converting them into selection parameter values, CHS procurement executives had to select the supplier. The selection process included several stages. At first, each set of criteria received a relative weighting based on the decision makers' subjective preferences and as suggested by several studies [3]. A weight of 0.4 was given to the Supply criteria set, and a 0.6 weight was given to the Supplier criteria set. Following that, a relative weight was given to each specific criterion based on the decision makers' perspective and their experience. Next, the decision makers were required to weigh the parameters relevant to supplier selection, based on their criterion weighting. Appendix 3 presents the weights as determined by CHS.

The selection parameter weights were determined in several phases. First, three importance levels were specified: high, medium and low. The weights were then determined based on the importance levels and the level of score variance in the various proposals per each selection parameter. For example, high importance combined with high variance in the supplier standard scores for the same parameter meant a high weight, while high importance combined with low variance meant a medium weight. Similarly, low importance combined with high variance meant a medium weight, while low importance combined with low variance meant a low weight. Whenever a certain criterion was represented by a single selection parameter, this parameter received the full weight of the criterion it represented.

The decision makers were then required to rate the various suppliers on each selection parameter. This rating was based on a specification of score scales for each parameter, $p_{k^{g} n^{g}}^{g}, g=1,2$, defined by a lower and upper boundary for each selection parameter, $L\left(p_{k^{g}, n^{g}}^{g}\right)$ and $U\left(p_{k^{g}, n^{g}}^{g}\right)$, respectively. The various scale ratings were determined by using two approaches based on parameter type. One was the 1-5 Likert scale (1 representing the lowest value), and the other was binary. A rating per each parameter, $d_{k^{g}, n^{g}}^{g}, g=1,2$, in each of the criteria group was computed using a transformation function substituting the selection parameter raw value $p_{k^{g}, n^{g}}^{g}$ by the rating value $d_{k^{g}, n^{g}}^{g}=\operatorname{Trans}\left(p_{k^{g}, n^{g}}^{g}\right)$, such that $d_{k^{g}, n^{g}}^{g} \in\left[L\left(p_{k^{g}, n^{g}}^{g}\right), U\left(p_{k^{g}, n^{g}}^{g}\right)\right]$. Appendix 2 presents the value transformation of all selection parameters $p_{k^{g}, n^{g}}^{g}$ into the rating scores $d_{k^{g}, n^{g}}^{g}$. For each supplier proposal $i=1,2,3,4$, the raw score $d_{k^{g}, n^{g}}^{g}$ was transformed into a standard score $x_{k^{g},^{g}}^{g}$ using a uniform 0-100 scale for each criteria set $g=1,2$, with 100 being the highest value for each parameter. Supplier proposal standard score sums for all selection parameters based on the Likert scaling approach following the transformation are presented in Appendix 1.

The binary approach was used to evaluate one remaining parameter: Quantity Discount. If the supplier offers such discount, he will receive the optimal 100 score. If not, the score will be 0 . Table 2 presents supplier data for this parameter.

Since $S 2$ had no historical data that could be used to specify the Reputation parameter, he received a 59.78 score on this parameter, equal to the proportional weighted average score of all the other selection parameters.

After specifying the weights for each parameter and determining the standard scores for supplier proposal, all that remained was to calculate the total weighted score for each supplier proposal. This was done by multiplying the relevant weight by the score, as suggested by the literature surveyed above and as prevalent in practice. The total score $X_{i}$ for each $i$ supplier proposal, $i=1,2,3,4$, was given by the following:

$$
\begin{aligned}
X_{i}= & \sum_{k^{1}=1}^{Q_{1}} \sum_{n^{1}=1}^{P_{k^{1}}^{1}} \omega\left(p_{k^{1}, n^{1}}^{1}\right) x_{i}\left(p_{k^{1}, n^{1}}^{1}\right)+ \\
& \sum_{k^{2}=1}^{Q_{2}} \sum_{n^{2}=1}^{P_{k^{2}}^{2}} \omega\left(p_{k^{2}, n^{2}}^{2}\right) x_{i}\left(p_{k^{2}, n^{2}}^{2}\right), i=1,2,3,4
\end{aligned}
$$

such that $\omega\left(p_{k^{g}, n^{g}}^{g}\right)$ is the weight of each parameter $p_{k^{g}, n^{g}}^{g}$, and $x_{k^{g}, n^{g}}^{g}$ is the standard score, $n^{g}=1,2 \cdots P_{k^{g}}^{g}$ $g=1,2$. Using this formula for the various suppliers produced the following final scores: $S 1=62, S 2=59.78$, $S 3=66, S 4=69$. On the basis of these scores $S 4$ was selected for the 2003-2007 contract.

\section{Constructing Dynamic Selection Weights}

\subsection{Proposed Methodology Principles}

As already mentioned, one of the key characteristics of modern business environments is their dynamics. Supplier selection must take this factor into account. Below, we propose a retrospective qualitative and quantitative description of environmental influences on supplier se lection considerations. No less important, we propose how to present them visually to the decision makers, so as to enable them to actually "see" the selected supplier, as well as predictable changes in the business environment.

First, the proposed methodology focuses on selecting a supplier under initial environmental conditions, as described in Part 2, on the basis of characterizing customer 
A Case Study in the Healthcare Services

Table 2. Standard scores for the quantity discount parameter $\left(p_{3,1}^{2}\right)$.

\begin{tabular}{lccccc}
\hline & Supplier & S1 & S2 & S3 & S4 \\
\cline { 2 - 6 } Selection parameter & Standard score & 0 & 100 & 0 & 0 \\
quantity discount $\left(p_{3,1}^{2}\right)$ & Supplier proposal & None & V & None & None \\
\hline
\end{tabular}

requirements, specifying selection criteria, subjectively weighting them in a way that reflects the decision makers' preferences and finally, scoring these criteria. We then present a supplier selection process based on selection criteria under dynamic environmental conditions. The selection criteria specified (see Appendix 1) are based on the supplier selection literature, mainly Dickson [11]. Using these selection parameters, we can analyze the supplier selection process in the organization studied, as it is affected by its dynamic business environment. In general, the selection criteria would be quantitative, but they may also be qualitative as long as measurable selection parameters could be tailored for them.

\subsection{Dynamic Weight Functions}

As already described, following environmental changes specifically, rising raw material prices-CHS's latex glove supplier raised its price subject to the contract. Following that move, CHS found itself tied to a less-than-optimal supplier, and in retrospect, realized that it should have been able to select a new supplier able to meet such price fluctuations. Following the changes in the business environment, the original weights and scores given to the four latex glove suppliers were no longer appropriate. The decision assessed in retrospect in this case study refers to the following question: what is the future date in which it would no longer be worthwhile to continue working with the present supplier? In order to specify a dynamic environment that would expand the scope of supplier selection beyond the rise in raw material prices to factor in additional environmental influences, we have identified relevant dynamic environmental parameters $p_{j}, j=1,2,3,4,5$ using research tools [23], as well as an internal questionnaire distributed among CHS's procurement executives. Table 3 presents these parameters and their initial values.

In order to represent various environmental influences using dynamic environment parameters we suggest constructing dynamic weight functions. Moreover, in order to enable decision makers to construct relatively simple weight functions, we propose an initial qualitative presentation of the directions of environmental parameter influences on each selection parameter. Table 4 presents the direction in which each environmental parameter is expected to influence the selection parameter weight according to the decision makers' perspective. For each selection parameter, the table presents changes which would make it more difficult to conduct business in the given environment. These changes could cause certain selection parameters to "gain weight", and others to "lose weight". For example, a sharp increase in the Demand parameter, for example, would require suppliers to supply greater quantities, thus casing the selection parameter Max per Shipment to gain weight. Similarly, an increased Interest Rate would cause Inventory Maintenance cost to gain weight; reduced Supply Time affects the suppliers' ability to prepare for the next shipment, thus affecting some of the selection parameters, such as Geographic Location; finally, lower Raw Materials Supply would cause the supplier to increase the Cost per Unit, so that this parameter would gain weight.

The thin arrows in Table $4(\downarrow)$ indicate the desirable direction of response, according the decision makers' subjective interpretation of changes in the selection parameter weights following the negative environmental changes. Whenever a CHS decision maker can be expected to be indifferent to the parameter weight change, no arrow appears. Therefore empty cells represent indif ference by the decision makers regarding the required response to the change in the environmental parameter in question.

The thick arrows in Table $4(\Downarrow)$ indicate worsening in environmental parameter values: higher Demand, higher Interest Rate, lower Supply Time, lower Raw Material Supply and higher Exchange Rate.

To illustrate the logic filling out the table shown above, we will refer to the Min per Shipment selection parameter. When demand is rising, this parameter would lose weight, since under the new conditions, larger shipments are desirable. This parameter would gain weight as the

Table 3. Business environment parameters: Initial 2002.

\begin{tabular}{|c|c|c|c|c|c|}
\hline $\begin{array}{c}\text { Environmental } \\
\text { Parameter }\end{array}$ & $\begin{array}{c}\text { Annual } \\
\text { Demand }(d)\end{array}$ & Interest Rate $(r)$ & $\begin{array}{c}\text { Supply } \\
\text { Time }(D D)\end{array}$ & $\begin{array}{l}\text { Raw Material } \\
\text { Supply }(n n)\end{array}$ & $\begin{array}{c}\text { Nis-to-Dollar Exchange } \\
\text { Rate (cur) }\end{array}$ \\
\hline Initial Value & 10 & 0.1 & 5 & 100 & 4.8 \\
\hline
\end{tabular}


Table 4. Worsening environmental parameter values and their effect on parameter weights.

\begin{tabular}{|c|c|c|c|c|c|}
\hline Environmental Influence/Selection Parameter & $\begin{array}{c}\text { Demand } \\
\Uparrow\end{array}$ & $\begin{array}{c}\text { Interest Rate } \\
\Uparrow\end{array}$ & $\begin{array}{c}\text { Supply Time } \\
\Downarrow\end{array}$ & $\begin{array}{c}\text { Raw Material Supply } \\
\Downarrow\end{array}$ & $\begin{array}{c}\text { Exchange Rate } \\
\Uparrow\end{array}$ \\
\hline Minper Shipment $p_{1,1}^{1}$ & $\downarrow$ & $\uparrow$ & $\uparrow$ & & $\uparrow$ \\
\hline Maxper Shipment $p_{1,2}^{1}$ & $\uparrow$ & $\downarrow$ & $\downarrow$ & & $\downarrow$ \\
\hline Unit Cost $p_{2,1}^{1}$ & $\uparrow$ & $\uparrow$ & & $\uparrow$ & $\uparrow$ \\
\hline Expected Defect Rate $p_{3,1}^{1}$ & & & $\uparrow$ & $\uparrow$ & \\
\hline Suggested Supply Time $p_{1,1}^{2}$ & $\uparrow$ & & $\uparrow$ & $\uparrow$ & \\
\hline Credit Rating $p_{1,2}^{2}$ & $\uparrow$ & & & $\uparrow$ & $\uparrow$ \\
\hline Reputation $p_{1,3}^{2}$ & $\uparrow$ & & $\uparrow$ & $\uparrow$ & \\
\hline Order Cost $p_{2,1}^{2}$ & $\downarrow$ & $\uparrow$ & & & $\uparrow$ \\
\hline Quantity Discount $p_{3,1}^{2}$ & $\uparrow$ & $\downarrow$ & & $\downarrow$ & $\downarrow$ \\
\hline Geographic Location $p_{3,2}^{2}$ & & & $\uparrow$ & $\uparrow$ & \\
\hline Payment Date $p_{3,3}^{2}$ & $\uparrow$ & $\uparrow$ & & & $\uparrow$ \\
\hline Minper Order $p_{4,1}^{2}$ & $\downarrow$ & $\uparrow$ & & & $\uparrow$ \\
\hline Maxper Order $p_{4,2}^{2}$ & $\uparrow$ & $\downarrow$ & & & \\
\hline
\end{tabular}

interest rate (as it affects inventory maintenance costs) increase. The reason for that is that due to the higher interest rate, the organization would rather keep inventories to a minimum, and attach a higher weight to the minimal supplied quantities, assuming they are proportional to order size. When environmental conditions cause supply time to shrink, this parameter's weight would increase again, since given shorter supply time it is important to make sure that at least a minimal amount of the product would arrive in each shipment, or that working with smaller shipments is made possible. A rising exchange rate would also increase the weight of this parameter, since when product cost is high the organization would require smaller quantities in each shipment, hence the greater importance attached to the supplier's ability to supply minimal quantities. As opposed to all these clear outcomes, reduced raw material supply would have an ambiguous effect: on the one hand, it could cause item costs to rise, reducing the Min per Shipment parameter weight as the organization would want to keep a minimal inventory as product costs rise; on the other hand, reduced supply could cause buyers to increase their demand as they fear future shortage, leading to the opposite effect. CHS decision makers would therefore remain indifferent to this environmental change.

After having specified the directions of environmental influences, we now need to specify a more detailed functional structure for calculating selection parameter weighs as they are affected by these influences. In order to construct more accurate functions and adjust them to the directions presented above, we have studied the effect of such environmental changes using a sensitivity analysis in a decision maker trial and error approach by changing the present environmental values in retrospect and assessing their impact on the desirable weight of each selection parameter. To simplify application without loss of generality we have chosen two dynamic weight functional structures. One has a linear product coefficient $y=a x+b$, such that $a, b$ are parameters subjectively determined to obtain the function's specific configuration. In functions of this type, a dynamic product coefficient of a selection parameter weight with general indexes for some dynamic environmental parameter $p^{\text {dym }}$ describing an influence on a certain selection parameter would be $f\left(p^{d y m}\right)=\left(\frac{1-b}{p^{d y m, \text { cur }}}\right) p^{\text {dym }}+b$, such that $b$ represents the decision maker's subjective sensitivity to the degree of change in the selection parameter weight relative to the change in the external parameter $p^{d y m}$, while $p^{d y m, c u r}$ is the present value of $p^{d y m}$. The second type are dynamic weight functions with an exponential structure, $y=\alpha e^{\beta x}$, such that $\alpha, \beta$ are subjectively determined parameters for obtaining the function's specific configuration. In functions of this type, the dynamic product coefficient $f\left(p^{d y m}\right)=\alpha^{-\frac{p^{d y m}}{p^{d y m}, \text { cur }}+1}$ of the selection parameter weight, for a certain environmental parameter $p^{d y m}$ describes an influence on a given selection parameter, such that parameter $\alpha$ represents the 
decision maker's subjective sensitivity to the degree of change in the selection parameter weight relative to the change in the external parameter $p^{d y m}$.

The choice of a certain functional structure will be subject to the given selection parameter weight's sensitivity to changes in the business environment over a specific horizon, based on the decision makers' final determination. An exponential structure would enable to represent a varying sensitivity of selection parameter weight as dependent on environmental parameter values.

In order to calculate the dynamic weight of a certain selection parameter as a functional dependency on environmental parameter values, we must first multiply the product coefficients of all the various environmental parameters by the selection parameter's initial weight. The assumption behind this coefficient multiplication approach is mutual independence of the selected parameter values representing environmental changes. This independence guides their selection even if it is unnecessary for application purposes. When the decision maker is indifferent, the product coefficient value is set to 1 . A schematic representation of a linear dynamic product coefficient structure is presented in Figure 3, with the example of Min per Shipment as it changes relative to Demand.

In order to represent the desirable directions of changing selection parameter weights in response to changes in parameter values (Table 4), CHS decision makers have specified subjective parameter values to obtained detailed descriptions of linear or exponential dependence of each selection parameter on environmental parameters. These subjective parameters are presented in Appendix 4. This specification is based on a graphic representation of influences as shown above, and on a calibration of subjective parameter values using visual trial and error, as represented in the example in Figure 3. Specifying a while setting a subjective parameter $b$ means a linear

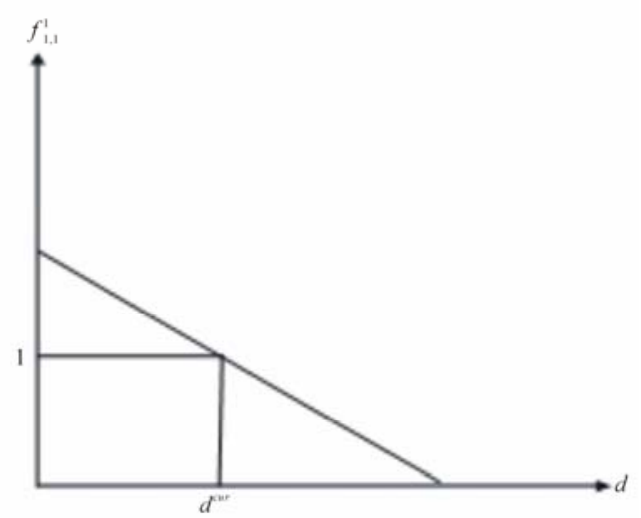

Figure 3. Dynamic product coefficient of min per shipment as a function of annual demand. subjective parameter $\alpha$ means exponential influence, influence. An empty cell in the table means the decision maker is indifferent with regard to the desirable response.

Equation (2) is an example of a dynamic weight function for selection parameters as dependent on environmental parameters. The dynamic weight function for Min per Shipment, prior to normalization calculation, is given by

$$
\begin{aligned}
f_{1,1}^{1, d, i, D D, \text { cur }} & =0.1 \cdot\left(1.7^{-\frac{d}{d_{0}}+1}\right) \cdot\left[\left(\frac{1-(-2)}{i_{0}} \cdot i\right)-2\right]\left[\left(\frac{1-3}{D D_{0}} \cdot D D\right)+3\right] \cdot \\
& \cdot\left(0.04^{-\frac{\text { Cur }}{\text { Cur }_{0}}+1}\right)
\end{aligned}
$$

In itself, the requirement that the total dynamic selection parameter weights for all parameter values adding up to 1 does not guarantee that all requirements for parameter weight change trends as represented in Table 5 will in fact be met. One reason is the differences in the specific intensities of change sensitivity as determined by CHS decision makers for the weight of each selection parameter relative to each environmental parameter. Another is the possible existence of requirements to enable opposing trends. The weights obtained by the dynamic weight functions for the various selection parameters must be normalized. The normalization requirement is such that the total weights of all selection parameters add up to 1 per each future environmental parameter vector value. Table 5 presents selection parameter weights as a result of business environment changes versus the initial selection parameter weights, in reference to a $5 \%$ worsening in all environmental parameters. The environmental parameter change directions are presented in Table 5 .

\subsection{Dynamic Weight Functions}

In order for the CHS decision makers to be able to easily select the supplier given changes in their business environment, we have plotted each environmental parameter on a two-dimensional graph, with the horizontal axis representing the environmental parameter value and the vertical axis represented the selected supplier index, such that all other environment values remain constant at their current values (given in Table 4).

Looking at Figure 4, we can see that $S 3$ becomes dominant when the required supply time shrinks. This is because this supplier excels in relevant selection parameters such as Reputation and Supply Time which gain weight the more Supply Time shrinks. High scores in these parameters, together with their increased weight, raise S3's general score. Similarly, Figure 5 shows that when Supply falls, $S 3$ becomes dominant as it excels in 
Table 5. Selection parameter weights: current vs. dynamic environment (5\% worse).

\begin{tabular}{|c|c|c|}
\hline Selection Parameter & Current Parameter Weight & Dynamic Parameter Weight \\
\hline Minper Shipment $p_{1,1}^{1}$ & 0.1 & 0.07 \\
\hline Maxper Shopment $p_{1,2}^{1}$ & 0.07 & 0.03 \\
\hline Unit Cost $p_{2,1}^{1}$ & 0.15 & 0.04 \\
\hline Expected Defect Rate $p_{3,1}^{1}$ & 0.08 & 0.04 \\
\hline Suggested Supply Time $p_{1,1}^{2}$ & 0.1 & 0.11 \\
\hline Credit Rating $p_{1,2}^{2}$ & 0.06 & 0.05 \\
\hline Reputation $p_{1,3}^{2}$ & 0.07 & 0.09 \\
\hline Order Cost $p_{2,1}^{2}$ & 0.1 & 0.06 \\
\hline Quantity Siscount $p_{3,1}^{2}$ & 0.03 & 0.01 \\
\hline Geographic Location $p_{3,2}^{2}$ & 0.03 & 0.03 \\
\hline Payment Date $p_{3,3}^{2}$ & 0.04 & 0.06 \\
\hline Minper Order $p_{4,1}^{2}$ & 0.07 & 0.04 \\
\hline Maxper Order $p_{4,2}^{2}$ & 0.1 & 0.04 \\
\hline
\end{tabular}

relevant selection parameters such as Reputation and Supply Time which gain in weight as Supply falls. High scores in these parameters, together with their increased weight, raise S3's general score. Finally, we can see that a highly significant fall in Supply may lead to selecting S1, which excels in the Supply Time and Geographic Location selection parameters which gain in weight as Supply falls.

Figure 6 presents a three-dimensional graph illustrating the selected supplier's identity as a function of changes in two environmental parameters - Demand and Raw Material Supply-with the others held constant. The horizontal axes represent two environmental parameters changing concurrently, and the vertical axis is the sup- plier index. The figure shows that $S 1$ has now become almost irrelevant, although Figure $\mathbf{5}$ has shown it to be potentially relevant following a significant reduction in supply. This shows that the previous conclusion is inapplicable once demand changes as well. This information would lead decision makers to assume that $S 1$ would probably not be relevant in the future, both due to the high probability of demand changes and due to the trend of reduced supply time.

In order to identify the best supplier in different points in time, as a function of the previously specified environmental parameters, $\left[p_{1}, p_{2}, \cdots p_{E}\right]$, we can use the term $\arg \left(\max _{i} X_{i}\left(p_{1}, \cdots p_{E}\right)\right)$, where

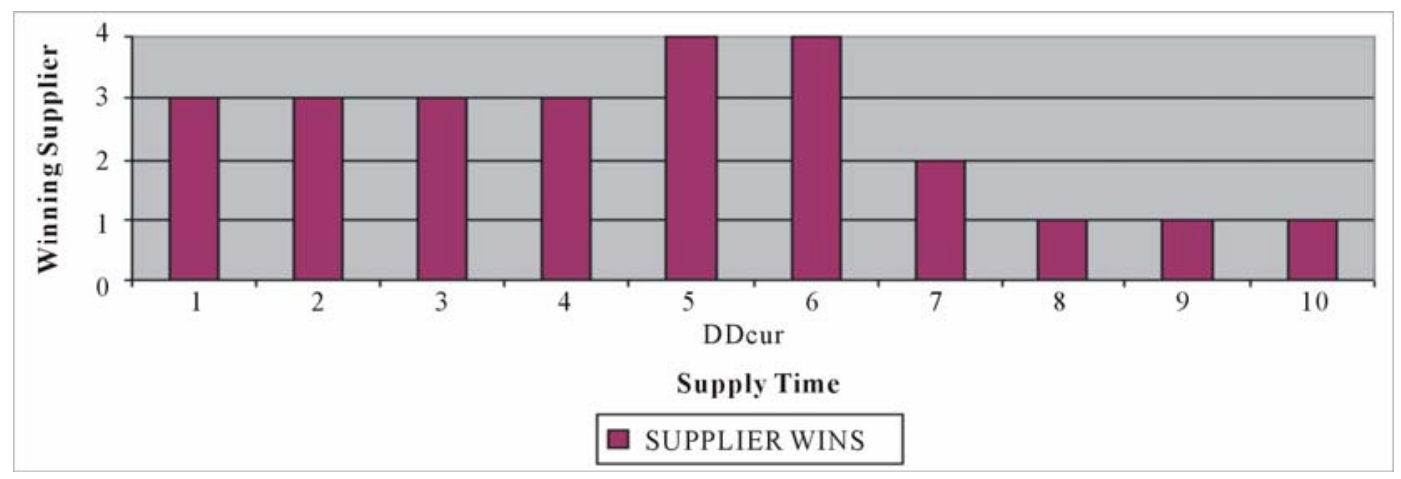

Figure 4. Selected supplier as a function of supply time change (DD). 


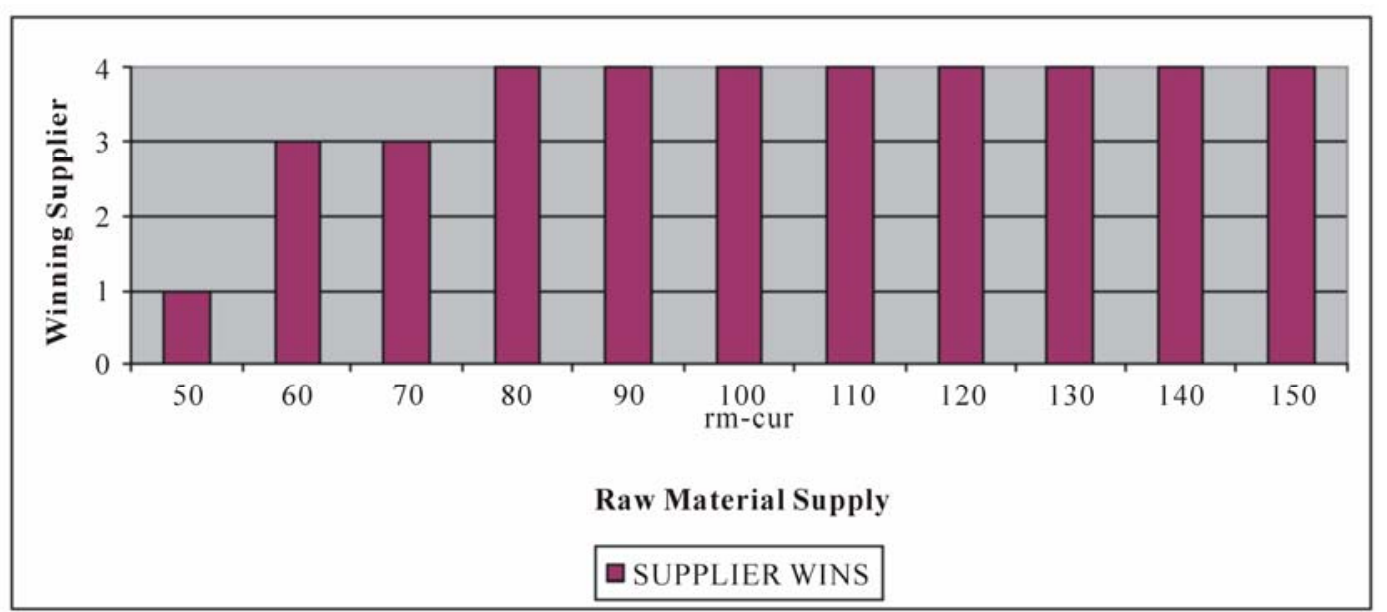

Figure 5. Selected supplier as a function of saw material supply (rm).

$$
\begin{gathered}
X_{i}\left(p_{1}, \cdots p_{E}\right)=\sum_{g=1}^{2} \sum_{k^{1}=1}^{Q_{1}} \sum_{n^{1}=1}^{P_{k^{1}}^{1}} \omega\left(p_{k^{g}, n^{g}}^{g, d y n}\right) x_{i}\left(p_{k^{g}, n^{g}}^{g}\right) \\
, i=1,2,3,4
\end{gathered}
$$

and $X_{i}\left(p_{1}, \ldots p_{E}\right)$ is a dynamic score for proposal $i$. The $X_{i}\left(p_{1}, \ldots p_{E}\right)$ score is composed of the standard scores $x_{i}\left(p_{k^{g}, n^{g}}^{g}\right)$ in proposal $i$ for the selection parameter $p_{k^{g}, n^{g}}^{g}$ and dynamic weights $\omega\left(p_{k^{g}, n^{g}}^{g, d y n}\right)$, normalized as dynamically dependent on the environmental parameters, according to the following:

$$
\begin{aligned}
\omega\left(p_{k^{g}, n^{g}}^{g, d y n}\right) & =\frac{f_{k^{g}, n^{g}}^{g}(d, r, D D, \text { rm }, \text { cur })}{\sum_{g=1}^{2} \sum_{k^{1}=1}^{Q_{1}} \sum_{n^{1}=1}^{P^{1}} f_{k^{g}, n^{g}}^{g}(d, r, D D, \text { rm }, \text { cur })} \\
, g & =1,2, k^{g}=1,2 \cdots Q_{g}, n^{g}=1,2 \ldots P_{k^{g}}^{g}
\end{aligned}
$$

weight coefficient functions and are presented in Appendix 4 . This formula dictates the supplier scores according to which the most desirable supplier is identified - the one with the highest score at each potential environmental point.

\section{Strategy for Replacing Suppliers over the Planning Horizon}

As already described, in 2002 the CHS Procurement Administration began evaluating potential latex glove suppliers. CHS chose one out of four candidates for a long-term contract. Hereafter, this strategy will be called the Basic Strategy. According to the Basic Strategy, the fourth supplier (S4) has been selected on the basis of its scores at the beginning of the planning horizon and is not replaced throughout it. Conversely, in our proposed methodology the procurement executives would have relied on CHS's periodic future planning information system to apply a strategy that takes into account business environment forecasts over the planning period to predict future points in time in which the most desirable supplier would change. The retrospective forecast presented in Figures 7-11 enables CHS to formulate a strategy for replacing suppliers following environmental changes over the 5-year planning horizon. Regrettably, in reality CHS continued to adopt the Basic Strategy of working with a single supplier throughout the planning period, regardless of environmental changes.

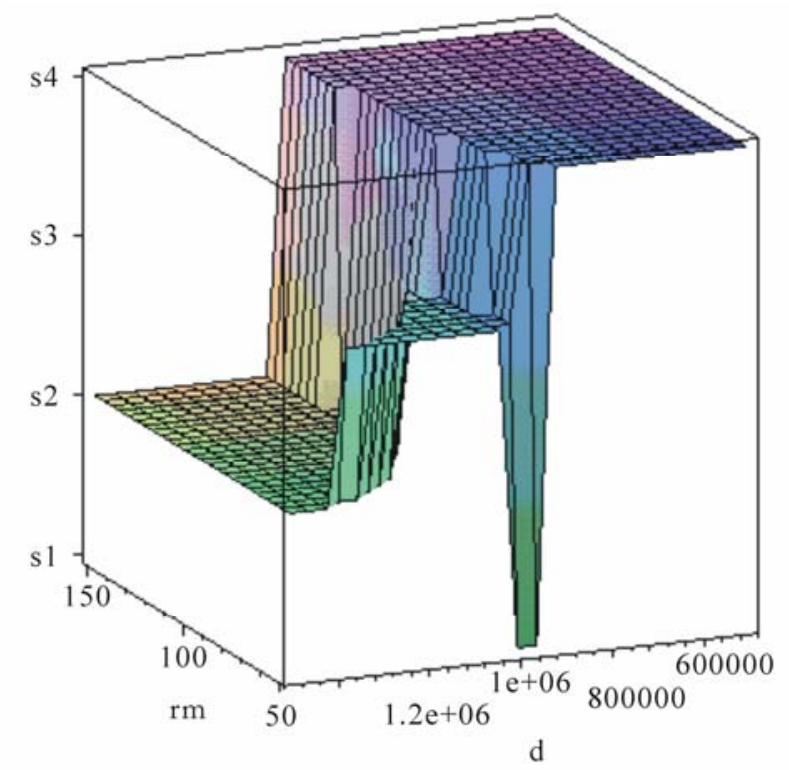

Figure 6. Selected supplier as a function of changing demand and raw material supply. 


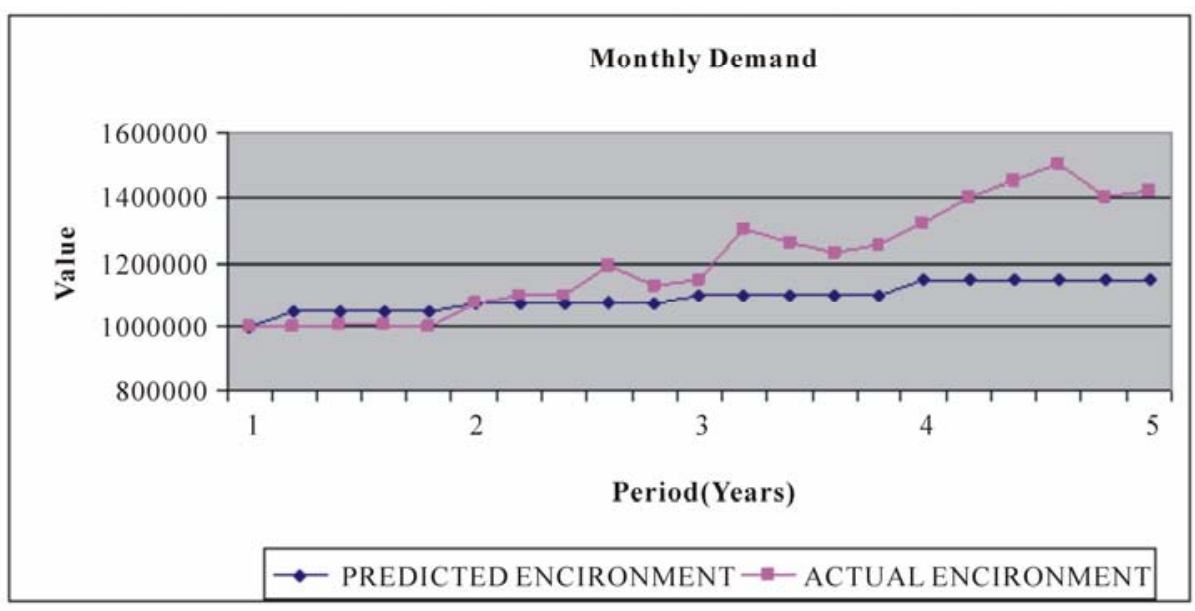

Figure 7. 2003-2007 demand forecast vs. realization.

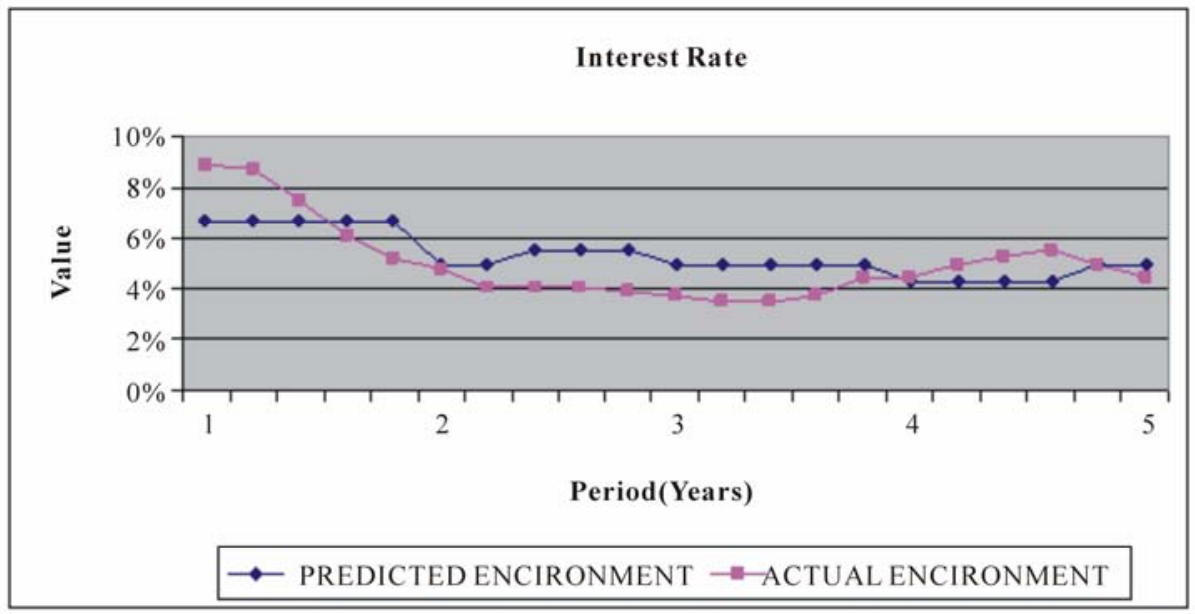

Figure 8. 2003-2007 interest rate forecast vs. realization.

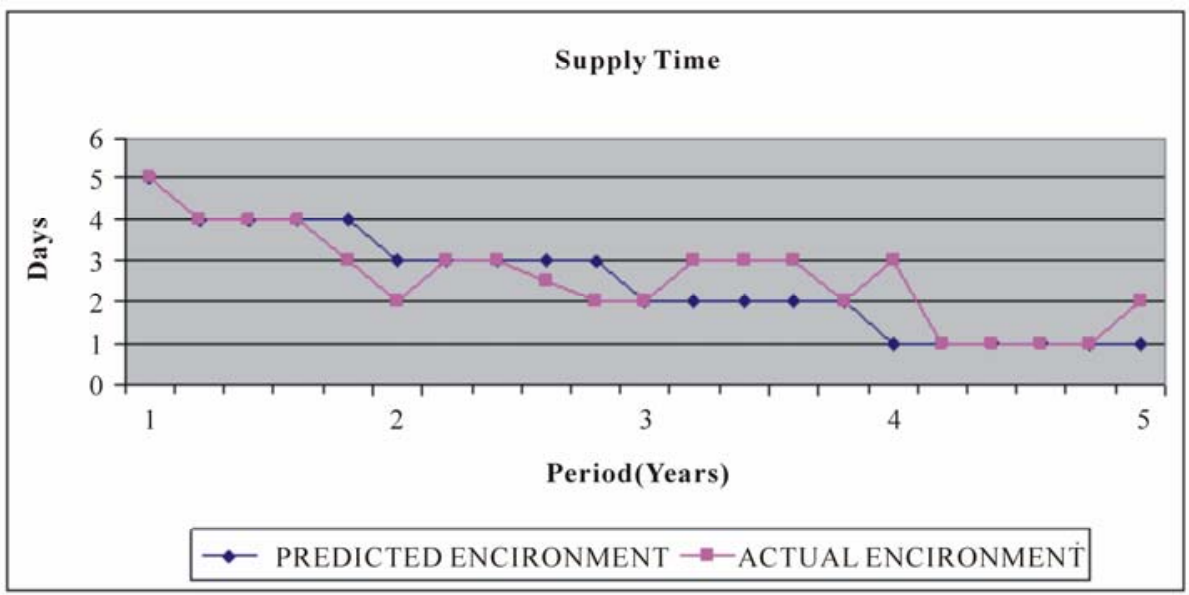

Figure 9. 2003-2007 supply time forecast vs. realization. 


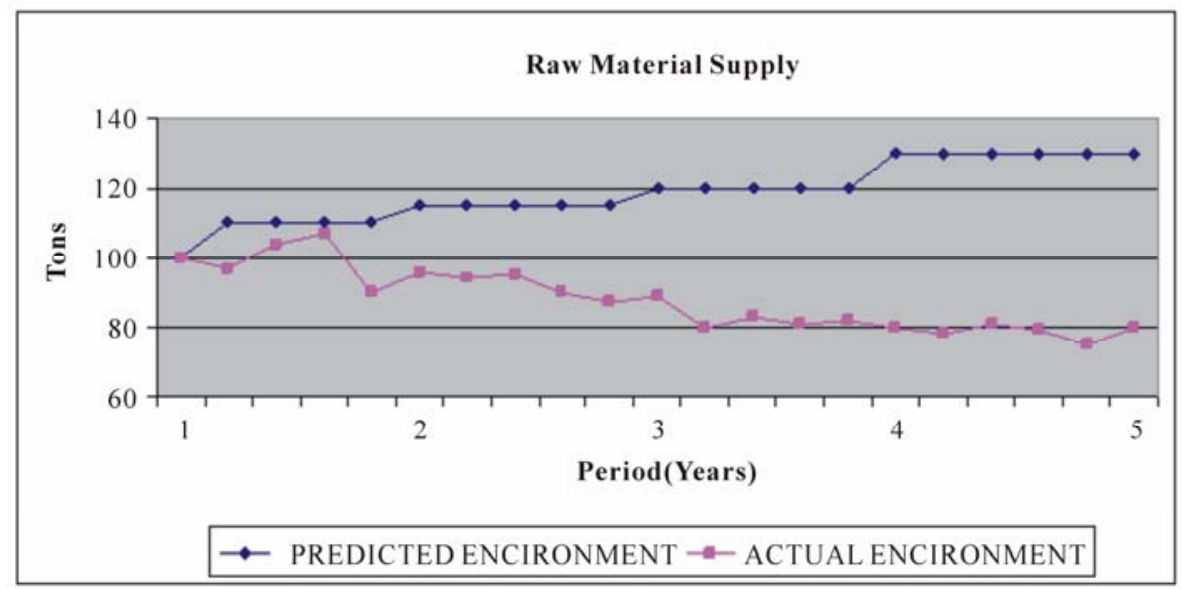

Figure 10. 2003-2007 raw material supply forecast vs. realization.

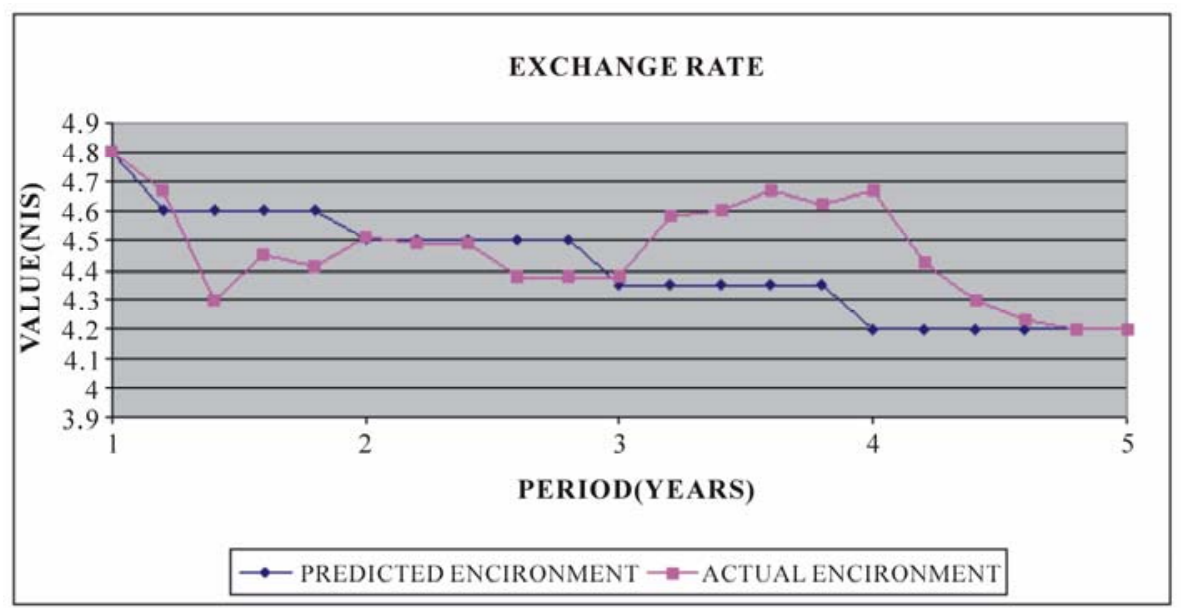

Figure 11. 2003-2007 exchange rate forecast vs. realization.

Figures 7-11 present the environmental parameter forecast for the entire planning period together with the parameter values as observed in reality, for the same planning period (2003-2007), with Year 1 referring to 2003, and so on.

The nature of competing strategies is evaluated based on actual environmental changes throughout the planning horizon. The strategy suggested here can provide decision makers with a series of future suppliers already at the beginning of the planning horizon. Figure 12 presents the predictable environmental forecasting strategy for the winning supplier over the planning horizon. The winning supplier's scores were evaluated every quarter for the five-year period. One can see how this strategy requires suppliers to be changed in midstream. Note that S2 would become preferable near the end of the planning horizon. This can be explained by the fact that the forecast predicts rising demand. A change of this type could lead to significantly higher weighting of the Unit Cost parameter, in which $S 2$ is much preferred over the others.

In order to fully appreciate the appropriateness of the decision to remain with a single supplier, compared to the retrospective choice of adopting a strategy that allows for supplier replacement in response to predictable environmental changes, we have specified a utility value per time unit based on the selected supplier score at that point in time. This utility indicator is based on actual environmental data for the period in question. The comparison is between the Predictable Environment Strategy and the Basic Strategy, in reference to actual environmental parameter values. As before, we calculate the winning supplier scores given the two strategies on a per-quarter basis. The area under each curve in Figure 13 is defined as the utility value for the respective strategy over the planning horizons. 


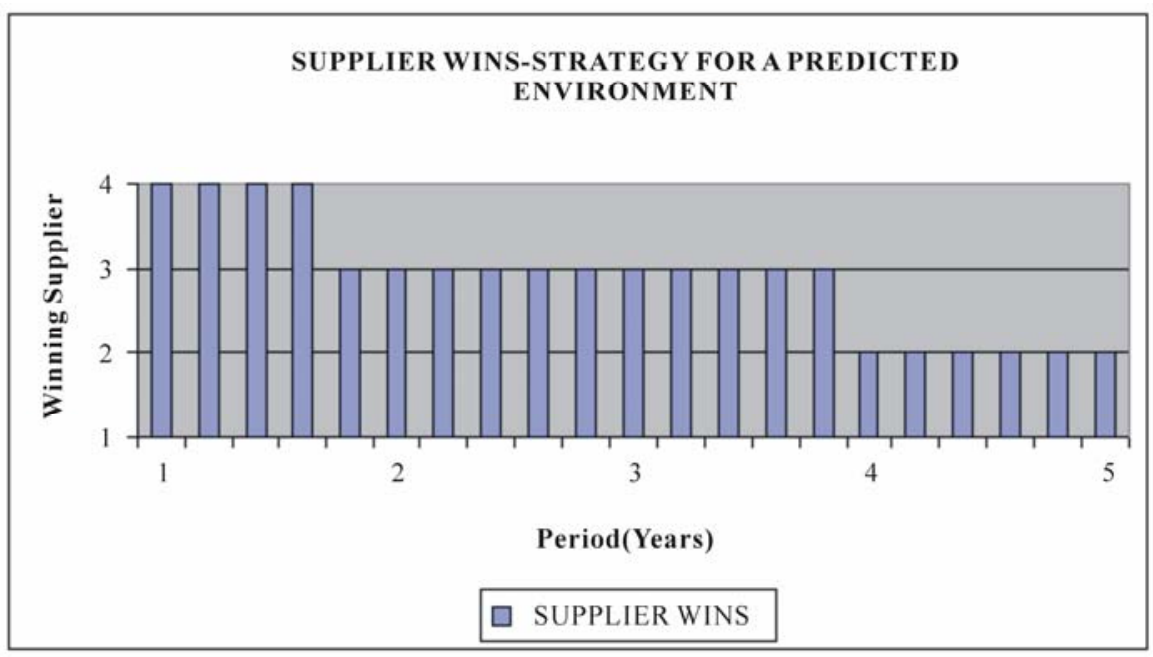

Figure 12. Predictable environment strategy.

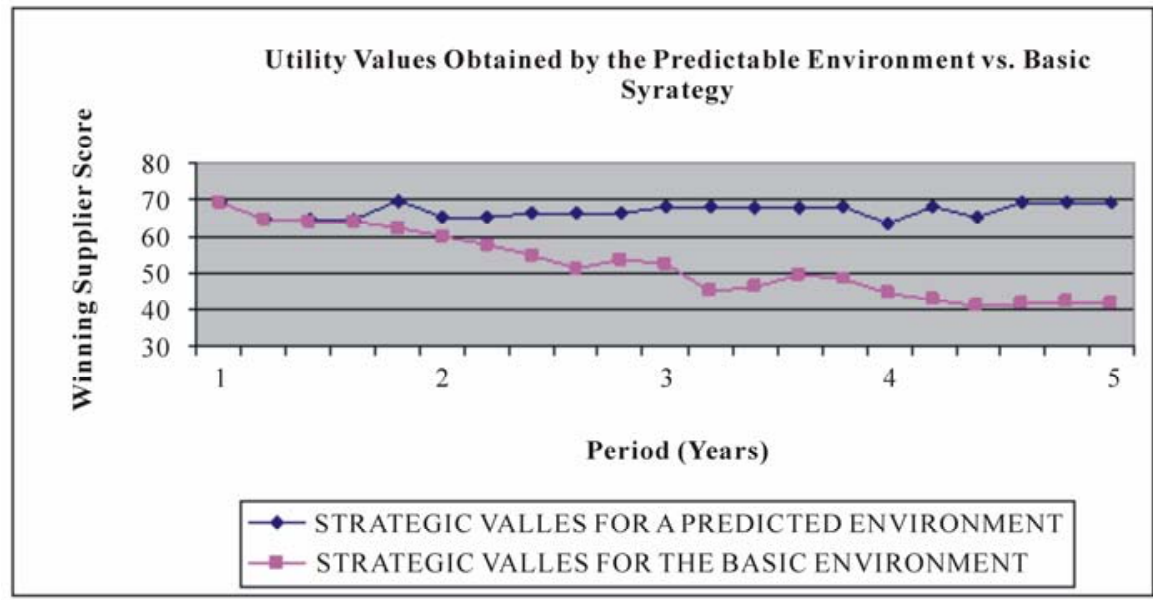

Figure 13. Utility values obtained by the predictable environment vs. basic strategy.

A comparison of the respective strategy utility values as presented in Figure $\mathbf{1 3}$ clearly shows that the Predictable Environment Strategy is preferable, and that in retrospect, CHS should have adopted this supplier replacement strategy. The difference between the utility values is around $20 \%$ in favor of the Predictable Environment Strategy. This aggregate improvement has been converted in Table 6 into several common operational indicators. The table shows that retrospective adoption of the proposed strategy would have ensured superior values of most indicators for the case under study.

The indicators presented in Table 6 have been calculated based on a raw average of each indicator over the planning horizon. Analysis of the utility data in this table demonstrates a significant economic efficiency gain, including savings of about $1,300,000$ NIS (about $\$ 350 \mathrm{~m}$ in current values) in Direct Purchasing Cost. This improvement is due to the fact that in the Basic Strategy, the selected supplier is $S 4$, which charges the highest Cost per Unit, while the Predictable Environment Strategy prioritizes $S 4$ only for about one fifth of the planning horizon. The environmental forecast points to a trend of continual gain in the Cost per Unit parameter, dictating a strategy of preferring suppliers excelling in this parameter as time goes by. In retrospect, the actual environmental parameter values moved closer to the predictable environment parameter values, mainly for the Demand parameter, which significantly affects the Cost per Unit parameter weight.

Further aspects of efficiency gain can be identified in other important parameters. This improvement is expressed in quantitative indicators, such as $14 \%$ shorter supplier range (Distance from Supplier), and 8\% shorter 
A Case Study in the Healthcare Services

Table 6. Operational indicator changes following retrospective adoption of the predictable environment strategy.

\begin{tabular}{|c|c|c|c|}
\hline Indicator & Basic Strategy & $\begin{array}{c}\text { Predictable Envionment } \\
\text { Strategy }\end{array}$ & Improvement \\
\hline Direct Purchasing Cost & $10,800,000$ NIS & $9,459,000$ NIS & $12 \%$ \\
\hline Supply Time & 3 days & 2.76 days & $8 \%$ \\
\hline Distance from Supplier & $120 \mathrm{~km}$ & $103 \mathrm{~km}$ & $14 \%$ \\
\hline Quantity Discount & 0 & 0.28 & $28 \%$ \\
\hline Payment Rating & Cutrent +75 days & Current +103 days & $37 \%$ \\
\hline Credit Rating & 2 & 2.52 & $26 \%$ \\
\hline Requtation & 40 & 77 & $92 \%$ \\
\hline Defective Rate PER Shipment & $0.4 \%$ & $0.53 \%$ & $-25 \%$ \\
\hline
\end{tabular}

Supply Time, as well as in qualitative indicators such as Credit Rating and Reputation. We can also see that there may be some indicators in which the Basic Strategy is retrospectively advantageous (e.g., Defective Rate per Shipment). S4's proposal in this latter parameter is the best among the four, so that not selecting it retrospectively had a negative effect. Although the predictable dynamics increased the weight of this parameter in relevant environmental scenarios, but this effect was relatively weak as it was felt in only two out of five environmental parameters (shorter Supply Time and smaller Raw Material Supply). In retrospect, the environmental forecast proved wrong, that is, it failed to approach the actual environment for the Raw Material Supply parameter, which had the main negative effect in terms of a $0.13 \%$ absolute increase in the Defective Rate per Shipment parameter.

\section{Discussion}

In this article, we have examined a new executive tool for supporting supplier selection, with particular reference to the dynamic nature of the organization's business environment. The methodology suggested here is based on a qualitative and quantitative description of environmental influences affecting present and future supplier selection consideration, and includes coherent visual representation of such effects to organizational decision makers. The methodology suggested was studied using a case study in a leading Israeli HMO, Clalit Health Services, which comprises large-scale logistical entities. In evaluating the methodology in this organization, we have assessed business environmental changes in retrospect, and particularly changes in such parameters which would have made it worthwhile for the organization to seek additional or alternative suppliers, or change the market shares of existing ones.

The proposed decision making process in Clalit Health Services has been accepted by its experts, based on a presentation of quantitative data in the application stages. Our case analysis shows that had the organization applied this methodology in retrospect, this would have improved most operational indicators by an average of $20 \%$. Nevertheless, the process does not guarantee that all indicators would improve, and some might even lose value.

An important key to the proposed methodology is determining a future series of suppliers, right at the beginning of the planning horizon. Admittedly, in some cases a policy of not replacing the selected supplier would be preferable. This is particularly true when the actual environment, as it develops over time, is significantly different from the one predicted in advance. Nevertheless, in such a case it is always possible to change the supplier replacement plan suggested by the proposed policy and adjust it to actual developments by updating the forecast on an ongoing basis. The resulting loss to the organization is expected to be smaller, on average, than the loss expected using the proposed strategy in this case.

One of the proposed methodology's assumptions is that existing supplier proposals, or at least the relative differences between them on all selection parameters, would be maintained throughout the planning horizon. Should that not be the case, we suggest updating the proposal scores from time to time, and changing preferences accordingly.

Our findings lead to the key conclusion that our methodology - the Predicted Environment Strategy - is preferable to the existing one applied by the organization over a broad range of operational indicators, and in terms of average total improvement. Despite the potential for 
non-negligible environmental prediction errors, in retrospect the proposed strategy's effectiveness has been shown to be maintained over a five-year planning period.

The proposed methodology may be applied to many other manufacturing and service organization, leading to economic and organizational efficiency gains. In all such organizations, decision makers can evaluate environmental parameters that are liable to change, leading to possible changes in the relative importance attached to the various supplier selection parameters. Moreover, the decision supporting executive tool suggested here takes the subjective element of decision making into account both by specifying environmental parameters affecting selection parameter weights and by specifying the weight functional structure (linear, exponential) affecting the degree of change. Consequently, this tool may quantitatively represent qualitative decision maker perspectives. Thanks to its simplicity, the methodology's applicability is maintained (apart from size proportions) also in systems that are characterized by a broad range of selection parameters liable to be affected by multiple business environmental parameters.

The proposed methodology is limited, however, when it comes to the application stage, where decision makers are required to subjectively determine parameters affecting the dynamic weight functions' configuration. It is possible to deal with this difficulty by using techniques allowing the identification of relevant parameters relying on partial data.

Another application limitation is the difficulty of selecting suppliers for a short term. For administrative reasons, or simply due to the bureaucratic difficulty of replacing suppliers over the short term, the proposed strategy might be applied only approximately and probably for long periods of time (years), as is customary. Moreover, the suggested policy could imply supplier replacement times in the order of days, or even hours. Although this constitutes no theoretical difficulty, in practice, supplier replacement dates would have to be adjusted to more manageable units, such as months or years.

One promising avenue of future research is to expand the validity basis of the proposed methodology by applying it to other organizations or using statistical simulation experiments. Another direction would be to enhance the subjective element in the abovementioned weight functional parameter selection and making it user-oriented on the methodological level. Developing an effective built-in trial-and-error mechanism could allow decision makers to better understand the significance of selecting certain parameters, and arrive at a more subjectively balanced parameter combination.

\section{REFERENCES}

[1] K. S. Bhutta and F. Huq, "Supplier Selection Problem: A Comparison of the Total Cost of Ownership and Analytic Hierarchy Process," Journal of Supply Chain Management, Vol. 7, No. 3, 2002, pp. 126-135.

[2] V. Jayaraman, R. Srivastava and W.C. Benton, "Supplier Selection and Order Quantity Allocation: A Comprehensive Model," Journal of Supply Chain Management, Vol. 35, No. 2, 1999, pp. 50-58.

[3] N. D. Singpurwalla, "A Probabilistic Hierarchical Classification Model for Rating Suppliers," Journal of Quality Technology, Vol. 31, No. 4, 1999, pp. 444-454.

[4] L. J. Bourgeois, "Strategy and Environment: A Conceptual Integration," The Academy of Management Review, Vol. 5, No. 1, 1980, pp. 25-39.

[5] R. B. Duncan, "Characteristics of Organizational Environments and Perceived Environmental Uncertainty," Administrative Science Quarterly, Vol. 17, No. 3, 1972, pp. 313-327.

[6] C. A. Weber, J. R. Current and W. C. Benton, "Vendor Selection Criteria and Methods," European Journal of Operations Research, Vol. 50, 1991, pp. 2-18.

[7] E. Timmerman, "An Approach to Supplier Performance Evaluation," Journal of Purchasing and Materials Management, Vol. 22, No. 4, 1986, pp. 2-8.

[8] L. E. Crow, R. W. Olshavsky and J. O. Summers, "Industrial Buyers' Choice Strategies: A Protocol Analysis," Journal of Marketing Research, Vol. 17, No. 1, 1980, pp. 34-44.

[9] C. C. Li, Y. P. Fun and J. S. Hung, "A New Measure for Supplier Performance Evaluation," Institute of Industrial Engineering, Vol. 29, No. 9, 1997, pp. 753-758.

[10] K. N. Thompson, "Scaling Evaluative Criteria and Supplier Performance Estimates in Weighted Point Pre-Purchase Decision Models," International Journal of Purchasing and Materials Management, Vol. 27, No. 1, 1991, pp. 27-36.

[11] G. W. Dickson, “An Analysis of Supplier Selection: Systems and Decisions," Journal of Purchasing, Vol. 2, No. 1, 1966, pp. 5-17.

[12] R. M. Monczka and S. H. Trecha, "Cost-Based Supplier Performance Evaluation," Journal of Purchasing and Materials Management, Vol. 24, No. 1, 1988, pp. 2-8.

[13] C. Muralidharan, N. Anatharaman and S. G. Deshmukh, "A Multi-Criteria Group Decision Making Model for Supplier Rating," Journal of Supply Chain Management, Vol. 38, No. 4, 2002, pp. 22-33.

[14] A. C. Pan, "Allocation of Order Quantity among Suppliers," Journal of Purchasing and Material Management, Vol. 25, No. 3, 1989, pp. 36-39.

[15] R. G. Kasilingam, "Selection of Vendors - a Mixed Inte- 
ger Programming Approach," Computers and Industrial Engineering, Vol. 22, No. 1-2, 1996, pp. 347-350.

[16] J. D. Hong and C. Hayya, "Just-in-Time Purchasing: Single or Multiple Sourcing?" International Journal of Production Economics, Vol. 27, No. 2, 1992, pp. 171-181.

[17] C. A. Weber and L. M. Ellarm, "Supplier Selection Using Multi-Objective Programming: A Decision Support System Approach," International Journal of Physical Distribution and Logistics Management, Vol. 23, No. 2, 1993, pp. 3-14.

[18] G. Wang, S. H. Huang and J. P. Dismukes, "Product Driven Supply Chain Selection Using Integrated Multi-Criteria Decision Making Methodology," International Journal of Production Economics, Vol. 91, No. 2, 2004, pp. $1-15$.

[19] W. Soukup, "Supplier Selection Strategies," Journal of
Purchasing and Materials Management, Vol. 23, No. 2, 1987, pp. 7-12.

[20] Z. Liao and J. Rittscher, "A Multi-Objective Supplier Selection Model under Stochastic Demand Conditions," International Journal of Production Economics, Vol. 105, No. 1, 2008, pp. 150-159.

[21] P. Keles and J. C. Hartman, "Case Study: Bus Fleet Replacement," The Engineering Economist, Vol. 49, No. 3 , 2004, pp. 253-278.

[22] R. Verma and M. Pullman, "An Analysis of the Supplier Selection Process," International Journal of Management Science, Vol. 26, No. 6, 1998, pp. 739-750.

[23] R. A. D'Aveni and D. J. Ravenscraft, "Economies of Integration versus Bureaucracy Costs: Does Vertical Integration Improve Performance?" The Academy of Management Journal, Vol. 37, No. 5, 1994, pp. 1167-1206.

Appendix 1. Supplier proposal and their total standard scores.

\begin{tabular}{|c|c|c|c|c|c|}
\hline & Supplier & $S 1$ & $S 2$ & $S 3$ & $S 4$ \\
\hline \multicolumn{6}{|l|}{ Selection Parameter } \\
\hline \multirow{2}{*}{ Min per Shipment $p_{1,1}^{1}$} & Proposal & 10,000 & 10,000 & 5,000 & 1,500 \\
\hline & St. Score & 40 & 40 & 80 & 100 \\
\hline \multirow{2}{*}{ Max per Shipment $p_{1,2}^{1}$} & Proposal & 500,000 & $1,000,000$ & $1,500,000$ & $2,000,000$ \\
\hline & St. Score & 20 & 40 & 60 & 80 \\
\hline \multirow{2}{*}{ Unit Cost (NIS) $\quad p_{2,1}^{1}$} & Proposal & 0.15 & 0.12 & 0.17 & 0.18 \\
\hline & St. Score & 80 & 100 & 60 & 40 \\
\hline \multirow{2}{*}{$\begin{array}{l}\text { Defective Rate per } \\
\text { Shipment } p_{3,1}^{1}\end{array}$} & Proposal & 0.8 & 0.7 & 0.5 & 0.4 \\
\hline & St. Score & 40 & 60 & 80 & 80 \\
\hline \multirow{2}{*}{$\begin{array}{l}\text { Supply Time (days) } \\
p_{1,1}^{2}\end{array}$} & Proposal & 1 & 4 & 2 & 3 \\
\hline & St. Score & 100 & 40 & 80 & 60 \\
\hline \multirow{2}{*}{ Credit Rating $p_{1,2}^{2}$} & Proposal & 3 & 2 & 3 & 2 \\
\hline & St. Score & 60 & 40 & 60 & 40 \\
\hline \multirow{2}{*}{ Reputation $p_{1,3}^{2}$} & Proposal & High performance & N/A & $\begin{array}{l}\text { Very high perform- } \\
\text { ance }\end{array}$ & Low performance \\
\hline & St. Score & 80 & 59.78 & 100 & 40 \\
\hline \multirow{2}{*}{$\begin{array}{l}\text { Cost per Order (NIS) } \\
p_{2,1}^{2}\end{array}$} & Proposal & 700 & 780 & 850 & 615 \\
\hline & St. Score & 80 & 60 & 40 & 80 \\
\hline \multirow{2}{*}{$\begin{array}{l}\text { Distance from Sup- } \\
\text { plier } p_{3,2}^{2}\end{array}$} & Proposal & 20 & 60 & 120 & 120 \\
\hline & St. Score & 100 & 80 & 60 & 60 \\
\hline \multirow{2}{*}{$\begin{array}{l}\text { Payment Date (Cur- } \\
\text { rent+) } p_{3,3}^{2}\end{array}$} & Proposal & 60 & 90 & 75 & 120 \\
\hline & St. Score & 40 & 60 & 60 & 80 \\
\hline \multirow{2}{*}{ Min per Order $p_{4,1}^{2}$} & Proposal & 50,000 & 100,000 & 30,000 & 80,000 \\
\hline & St. Score & 80 & 40 & 80 & 60 \\
\hline \multirow{2}{*}{ Max per Order $p_{4,2}^{2}$} & Proposal & $10,000,000$ & $15,000,000$ & $5,000,000$ & $25,000,000$ \\
\hline & St. Score & 40 & 60 & 60 & 100 \\
\hline
\end{tabular}


A Case Study in the Healthcare Services

Appendix 2. Suggested likert-scale rank score transformation.

\begin{tabular}{|c|c|c|c|c|c|}
\hline Rating/Parameter & 1 & 2 & 3 & 4 & 5 \\
\hline Min per Shipment $p_{1,1}^{1}$ & $m>10 \cdot 10^{3}$ & $10 \cdot 10^{3} \geq m>7.5 \cdot 10^{3}$ & $0.75 \cdot 10^{4} \geq m>0.5 \cdot 10^{4}$ & $5 \cdot 10^{3} \geq m>2.5 \cdot 10^{3}$ & $m \leq 2.5 \cdot 10^{3}$ \\
\hline $\begin{array}{l}\text { Max per Shipment } \\
p_{1,2}^{1}\end{array}$ & $\mathrm{M} \leq 5 \cdot 10^{5}$ & $10^{6} \geq \mathrm{M}>5 \cdot 10^{5}$ & $1.5 \cdot 10^{6} \geq \mathrm{M}>10^{6}$ & $2 \cdot 10^{6} \geq \mathrm{M}>1.5 \cdot 10^{6}$ & $\mathrm{M}>2 \cdot 10^{6}$ \\
\hline Unit Cost $p_{2,1}^{1}$ & $c \geq 0.2$ & $0.18 \leq c<0.2$ & $0.16 \leq c<0.18$ & $0.14 \leq c<0.16$ & $c<0.14$ \\
\hline $\begin{array}{l}\text { Expected Defect Rate } \\
p_{3,1}^{1}\end{array}$ & $P \geq 1$ & $0.8 \leq P<1$ & $0.6 \leq P<0.8$ & $0.4 \leq P<0.6$ & $P<0.4$ \\
\hline $\begin{array}{l}\text { Suggested Supply } \\
\text { Time } p_{1,1}^{2}\end{array}$ & $L T \geq 5$ & $4 \leq L T<5$ & $3 \leq L T<4$ & $2 \leq L T<3$ & $L T<2$ \\
\hline Credit Rating $p_{1,2}^{2}$ & Cre $=1$ & Cre $=2$ & Cre $=3$ & Cre $=4$ & Cre $=5$ \\
\hline Reputation $p_{1,3}^{2}$ & $\begin{array}{l}\text { Very low } \\
\text { performance }\end{array}$ & Low performance & Medium performance & High performance & $\begin{array}{l}\text { Very high } \\
\text { performance }\end{array}$ \\
\hline Order Cost $p_{2,1}^{2}$ & $o c>900$ & $900 \geq O C>800$ & $800 \geq o c>700$ & $700 \geq O C>600$ & $o c \leq 600$ \\
\hline Quantity Discount $p_{3,1}^{2}$ & $D>200$ & $150<D \leq 200$ & $100<D \leq 150$ & $50<D \leq 100$ & $D \leq 50$ \\
\hline $\begin{array}{l}\text { Geographic Location } \\
p_{3,2}^{2}\end{array}$ & $C R \leq 30$ & $30<C R \leq 60$ & $60<C R \leq 90$ & $90<C R \leq 120$ & $C R>120$ \\
\hline Payment Date $p_{3,3}^{2}$ & $o>10^{5}$ & $10^{5} \geq o>0.75 \cdot 10^{5}$ & $0.75 \cdot 10^{5} \geq o>0.5 \cdot 10^{5}$ & $0.5 \cdot 10^{5} \geq 0>0.25 \cdot 10^{5}$ & $o \leq 0.25 \cdot 10^{5}$ \\
\hline Min per Order $p_{4,1}^{2}$ & $O \leq 5 \cdot 10^{6}$ & $0.5 \cdot 10^{7}<O \leq 10^{7}$ & $10^{7}<O \leq 1.5 \cdot 10^{7}$ & $10^{7}<O \leq 2 \cdot 10^{7}$ & $O>2 \cdot 10^{7}$ \\
\hline
\end{tabular}

The $p_{3,1}^{2}$ parameter - Quantity Discount - has been specified with a transformation which expresses a binary rating, as shown in the table below.

\begin{tabular}{cccc}
\hline Selection Parameter/ Rating & $\mathbf{0}$ & $\mathbf{1}$ \\
\hline$p_{3,1}^{2} \quad$ Quantity Discount & None & $\sqrt{ }$ \\
\hline
\end{tabular}

Appendix 3. Selection parameter weights.

\begin{tabular}{lc}
\hline Selection Parameter & Weight \\
\hline Min per Shipment $p_{1,1}^{1}$ & 0.1 \\
Max per Shipment $p_{1,2}^{1}$ & 0.07 \\
Unit Cost $p_{2,1}^{1}$ & 0.15 \\
Expected Defect Rate $p_{3,1}^{1}$ & 0.08 \\
Suggested Supply Time $p_{1,1}^{2}$ & 0.1 \\
Credit Rating $p_{1,2}^{2}$ & 0.06 \\
Reputation $p_{1,3}^{2}$ & 0.07 \\
Order Cost $p_{2,1}^{2}$ & 0.1 \\
Quantity Discount $p_{3,1}^{2}$ & 0.03 \\
Geographic Location $p_{3,2}^{2}$ & 0.03 \\
Payment Date $p_{3,3}^{2}$ & 0.03 \\
Min per Order $p_{4,1}^{2}$ & 0.04 \\
Max per Order $p_{4,2}^{2}$ & 0.07 \\
\hline
\end{tabular}


A Case Study in the Healthcare Services

Appendix 4. Subjective parameters in dynamic selection weights.

\begin{tabular}{|c|c|c|c|c|c|}
\hline Selection Parameter & $\begin{array}{l}\text { As a function of } \\
\text { annual demand }\end{array}$ & $\begin{array}{l}\text { As a function of } \\
\text { interest rate }\end{array}$ & $\begin{array}{l}\text { As a function of } \\
\text { supply time }\end{array}$ & $\begin{array}{l}\text { As a function of } \\
\text { raw material cost }\end{array}$ & $\begin{array}{l}\text { As a function of } \\
\text { exchange rate }\end{array}$ \\
\hline Min per Shipment $p_{1,1}^{1}$ & $\alpha=1.7$ & $b=-2$ & $b=3$ & & $\alpha=0.04$ \\
\hline Max per Shipment $p_{1,2}^{1}$ & $\alpha=0.08$ & $b=3$ & $b=-1$ & & $b=2$ \\
\hline Unit Cost $p_{2,1}^{1}$ & $\alpha=0.0001$ & $\alpha=0.0001$ & & $b=8$ & $\alpha=0.0001$ \\
\hline Expected Defect Rate $p_{3,1}^{1}$ & & & $b=6$ & $\alpha=0.05$ & \\
\hline Suggested Supply Time $p_{1,1}^{2}$ & $\alpha=0.0001$ & & $b=10$ & $\alpha=4$ & \\
\hline Credit Rating $p_{1,2}^{2}$ & $\alpha=0.0001$ & & & $b=2$ & $\alpha=0.05$ \\
\hline Reputation $p_{1,3}^{2}$ & $\alpha=0.0001$ & & $b=10$ & $b=5$ & \\
\hline Order Cost $p_{2,1}^{2}$ & $b=2$ & $\alpha=0.001$ & & & $b=3$ \\
\hline Quantity Discount $p_{3,1}^{2}$ & $b=-1.5$ & $b=4$ & & $b=-1.5$ & $b=4$ \\
\hline Geographic Location $p_{3,2}^{2}$ & & & $b=10$ & $b=10$ & \\
\hline Payment Date $p_{3,3}^{2}$ & $\alpha=0.0001$ & $\alpha=0.0003$ & & & $\alpha=0.0003$ \\
\hline Min per Order $p_{4,1}^{2}$ & $\alpha=2$ & $b=-2$ & & & $\alpha=0.002$ \\
\hline Max per Order $p_{4,2}^{2}$ & $\alpha=0.05$ & $b=2$ & & & $b=1.5$ \\
\hline
\end{tabular}

